

\title{
Development Accounting: Conceptually Flawed and Inconsistent with Empirical Evidence
}

\author{
Theodore R. Breton \\ Universidad EAFIT
}

August 20, 2014

\begin{abstract}
Development accounting depends on two simplifying assumptions, that economies can be represented by a common aggregate production function and that aggregate factors of production are paid their social marginal products. An aggregate production function can explain income across countries, but the mathematics of the aggregate production function and the empirical evidence both indicate that aggregate factors are paid a small fraction of their social marginal products. As a consequence, development accounting underestimates the income differences due to human capital and overestimates the differences due to TFP. This error cannot be corrected because human capital's social marginal product is not observable.
\end{abstract}

JEL Codes: E13, O11, O47

Key Words: Development Accounting, Human Capital, External Effects

*Universidad EAFIT, Carrera 49\#7 Sur-50, avenida Las Vegas, Medellin, Colombia ted.breton@gmail.com and tbreton@eafit.edu.co

574-250-5322 (home) 574-261-9334 (office) 574-261-9294 (fax) 


\section{Introduction}

Robert Solow [1957] created a simple methodology to calculate the fraction of the growth in output/worker due to growth in physical capital/worker and attribute the residual fraction to growth in total factor productivity (TFP). This methodology is known as growth accounting. The key elements in the methodology are the assumptions that 1) an economy can be represented by an aggregate production function that includes physical capital, labor, and TFP and 2) the factors of production are paid their social marginal product.

Solow did not claim that the assumptions in the methodology are true or provide any evidence to support them. He only observed that since the aggregate production function may be a legitimate concept and since it is common to assume that factors are paid their marginal product, it may not be unreasonable to make these assumptions.

Researchers have applied a similar methodology across countries to calculate the fraction of the differences in national income that are due to differences in capital/worker and the residual fraction due to national differences in TFP. This methodology is known as development accounting. Development accounting requires the additional assumption that all economies can be represented by the same aggregate production function. This assumption may not be unreasonable if national output and factors of production are measured using the same prices.

In this paper I examine whether development accounting is a valid methodology for determining the share of national income differences that are due to national differences in TFP. Since the validity of the methodology depends on the validity of its assumptions, I first examine the evidence on whether all national economies can be represented by the same aggregate production function. Subsequently, I examine whether aggregate factors of production are paid their social marginal products. 
My findings are mixed. While it seems that national output across countries can be explained reasonably well with a common aggregate production function, the mathematics of this function and the evidence do not support the assumption that the aggregate factors of production are paid their social marginal products. I show that the mathematics of this function specifies that the aggregate factors are paid only a fraction of their social marginal products and that the empirical evidence is consistent with this specification.

According to Hsieh and Klenow [2010], the current consensus in the development accounting literature is that differences in TFP explain over half of the differences in national income across countries. If this consensus still exists, it is mistaken because it depends on the assumption that human capital does not have any external effects. Since considerable evidence indicates that human capital has large external effects, differences in capital/worker across countries must explain considerably more than half of the differences in national income across countries, and the residual differences in TFP must explain considerably less.

If the aggregate production function includes human capital and labor, and the aggregate factors are not paid their social marginal product, then development accounting cannot be performed. Since workers in this function receive income accruing to both human capital and labor, the share of national income accruing to human capital is not identified in the national accounts data, and this share cannot be calculated from other data if the aggregate factors are not paid their social marginal products. So development accounting appears to be completely discredited as a valid technique for explaining income differences across countries.

This paper is organized as follows: Section II examines whether economies across countries can be represented by a common aggregate production function. Section III analyzes whether the assumption that aggregate factors are paid their social marginal product is consistent 
with the mathematics of an aggregate production function. Section IV reviews the empirical literature evidence estimating human capital's and physical capital's external effects. Section V reviews the current "consensus" methodology used in development accounting. Section VI concludes.

\section{Existence of a Common Aggregate Production Function}

In a Cobb-Douglas production function with constant economies of scale, if the factors of production are paid their marginal product, the exponent on each factor is the share of income the factor receives in a competitive market. If a common aggregate production function exists across countries, the exponent on physical capital should equal physical capital's share of national income in all of these countries. Bernanke and Gurkaynak [2001] present evidence that this share is relatively similar across countries and that on average it is about 35 percent.

Mankiw, Romer, and Weil [1992] show that Solow's two-factor aggregate production function is unsatisfactory because it requires a capital share of 60 percent to explain the crosscountry differences in national income. They show that when human capital $(\mathrm{H})$ is added to Solow's function, the estimated function can explain cross-country income differences with a value of $\alpha$ that is similar to physical capital's share of national income. Their function is: 1) $\quad Y=K^{\alpha} H^{\beta}(A L)^{1-\alpha-\beta}$

Where $\mathrm{Y}$ is output, $\mathrm{K}$ is physical capital, $\mathrm{H}$ is human capital, $\mathrm{L}$ is labor, and $\mathrm{A}$ is total factor productivity.

Mankiw, Romer, and Weil's [1992] empirical evidence supporting the model was criticized because they used the share of the secondary-school-age population enrolled in school as their measure of human capital flows, rather than a more inclusive measure of schooling [Dinopoulos and Thompson, 1999]. Other researchers have successfully addressed this critique. 
Breton [2004] presents evidence supporting the model that uses investment in schooling/GDP as the measure of human capital flows. Cohen and Soto [2007] present empirical evidence supporting the model that uses the average schooling attainment of adults between 15 and 64 as the measure of the human capital stock. Breton [2013] presents evidence supporting the model that uses the cumulative net investment in the schooling of the population of working age as the measure of the human capital stock.

All of these studies use Penn World Table data, which measure economic activity using a single set of prices to estimate the value of goods and services across countries. The cumulative evidence from these studies indicates that a single aggregate production function can represent economies at different levels of development, as long as human capital is included in the function and economic activity is measured with a single set of prices.

Breton's [2013] measure of human capital is consistent with the theoretical specification in the aggregate production function, which is a financial net capital stock. Using consistent measures for the stocks of physical and human capital, he estimates that $\alpha \approx \beta \approx 0.35$. With an additional variable to control for adverse health effects in sub-Saharan Africa, he shows that Mankiw, Romer, and Weil's aggregate production function in log form explains $95 \%$ of the variation in national income across 61 countries.

\section{Plausibility that Aggregate Factors are Paid Their Social Marginal Products}

The development accounting methodology assumes that the aggregate factors of production are paid their marginal products, which requires that their private and social marginal products are the same. The assumption that factors of production are paid their marginal products is plausible at the micro level, but less plausible at the macro level. The aggregate 
factors in an aggregate production function could have external effects on regional or national output that the factors in a firm's production function do not have on the output of the firm.

If an increase in an aggregate factor affects the social marginal product of the other aggregate factors in an aggregate production function, then the aggregate factors have external effects on aggregate output, which means they are paid less than their social marginal products. Conceptually this could occur even while factors of production at the micro level are paid their full marginal product, since the aggregate production function is not the sum of the micro production functions in the economy.

The normal assumption at the micro level is that an increase in a firm's use of human or physical capital does not affect their marginal products in the economy because the firm is too small to affect these relationships. As an example, since the marginal product of human capital $\left(\mathrm{r}_{\mathrm{h}}\right)$ is constant, it is paid its entire marginal product:

2) Private $\mathrm{r}_{\mathrm{h}}=\partial\left(\mathrm{r}_{\mathrm{h}} \mathrm{H}\right) / \partial \mathrm{H}=\mathrm{r}_{\mathrm{h}} \partial \mathrm{H} / \partial \mathrm{H}=\mathrm{r}_{\mathrm{h}}=\mathrm{MPH}$

But at the macro level an increase in aggregate human capital clearly affects its social marginal product, so $r_{h}$ is not constant, and aggregate human capital is paid only the $\beta$ share of its social marginal product:

3) Private share of social $r_{h}=\partial\left(r_{h} H\right) / \partial H=\partial((\beta Y / H) H) / \partial H=\beta M P H$

Since an increase in aggregate human capital also raises the social marginal products of the other aggregate factors (physical capital and labor), these factors receive the $\alpha$ and $1-\alpha-\beta$ shares of human capital's social marginal product as external effects:

4) $\quad$ External $\mathrm{MPH}$ to $\mathrm{K}=\partial\left(\mathrm{r}_{\mathrm{k}} \mathrm{K}\right) / \partial \mathrm{H}=\partial((\alpha \mathrm{Y} / \mathrm{K}) \mathrm{K}) / \partial \mathrm{H}=\alpha \partial \mathrm{Y} / \partial \mathrm{H}=\alpha \mathrm{MPH}$

5) External MPH to $\mathrm{L}=\partial(\mathrm{wL}) / \partial \mathrm{H}=\partial((1-\alpha-\beta) \mathrm{Y} / \mathrm{L}) \mathrm{L}) / \partial \mathrm{H}=(1-\alpha-\beta) \partial \mathrm{Y} / \partial \mathrm{H}=(1-\alpha-\beta) \mathrm{MPH}$ 
The mathematics in equations (2) and (3) shows that even if there are Cobb-Douglas production functions at both the micro and macro levels of the economy, the micro private MPH is much smaller than the macro social MPH; in fact, the private MPH is only the $\beta$ fraction of the social MPH. Since the three aggregate factors are mathematically identical in the aggregate production function, in a closed economy the social marginal product of each factor is allocated to all of the factors in accordance with the exponent on each factor.

So Solow's argument that it may not be unreasonable to assume that the factors in an aggregate production function are paid their social marginal product is wrong. The mathematics of the aggregate production function clearly specifies that these factors are paid only a fraction of their social marginal products.

Surprisingly, this finding does not invalidate the assumption that in a competitive market the aggregate factors receive their social marginal product. Even though the aggregate factors are not paid their social marginal products, an aggregate production function that is homogenous of degree one provides each factor's social marginal product to it through the combination of the direct payment and the external effects of the other two factors. In the case of human capital, it receives the $\beta$ share of the social marginal product of each factor of production, which adds up to the $\beta$ share of national income:

6) Income to $\mathrm{H}=\beta\left(\mathrm{r}_{\mathrm{k}} \mathrm{K}\right)+\beta\left(\mathrm{r}_{\mathrm{h}} \mathrm{H}\right)+\beta(\mathrm{wL})=\beta(\alpha \mathrm{Y})+\beta(\beta \mathrm{Y})+\beta(1-\alpha-\beta) \mathrm{Y}=\beta \mathrm{Y}$

Since the social marginal product of human capital $r_{h}=\beta Y / H$, the human capital factor continues to receive its social marginal product since $r_{h} H=\beta Y$.

So the empirical problem that arises in development accounting when the aggregate factors are not paid their social marginal product is not a theoretical problem. The problem is that if the aggregate factors are not paid their social marginal products, there is no way to 
determine $\beta$. The share of national income accruing to human capital is not observable in the national accounts because it is combined with the income accruing to (unschooled) labor (L). And the value of $\beta$ cannot be estimated from human capital's observable private marginal product because this private marginal product is smaller than the social marginal product.

\section{Evidence that Aggregate Factors Are Not Paid Their Social Marginal Product}

The mathematical specification in the aggregate production function that aggregate factors are not paid their social marginal product could be incorrect. Practioners of the development accounting methodology argue that there is no evidence that physical capital and human capital have external effects. Hall and Jones [1999] state, "We believe that there is little compelling evidence of such externalities, much less any estimate of their magnitudes.” (p. 89) Caselli [2004] states, “...Pritchett's review of the evidence is typical in finding very little empirical support for positive externalities. On the other hand, various versions of the educationas-signalling-device model, as well as models of rent seeking, imply that the social return to education is lower than the private return. This possibility is quite compelling." (pp. 34-35)

It is only recently that numerous empirical studies have found that human capital has large external effects on personal income and on investment in physical capital. The studies of the external effects of human capital estimate the effect of the individual's and the region's level of schooling on individual incomes. The region may be a city or some other political jurisdiction, and the measures of regional human capital may be the share of the population with a university degree or the region's average schooling attainment. The empirical results vary by country, by the individual's level of schooling, and over time, but most studies find that regional levels of schooling have large external effects on individual incomes. 
Moretti [2004] finds that a $1 \%$ increase in college graduates in a U.S. city in the 1980s raised the wages of primary school graduates by $1.9 \%$, of secondary school graduates by $1.6 \%$, and of college graduates by $0.4 \%$. Sand [2013] replicates Moretti's findings for the $1980 \mathrm{~s}$, but for the 1990s he finds positive external effects only for college graduates and negative effects for less-educated workers. Huermann [2011] finds large external effects of higher regional education on workers' incomes in Germany between 1975 and 2001. A 1\% increase in highlyskilled workers increased wages of highly-skilled workers by $1.8 \%$ and non-highly-skilled workers by $0.6 \%$. Liu [2007] finds that a one-year increase in average schooling in Chinese cities in 1995 increased average earnings between 5 and 7\%.

For the purposes of this analysis, another study by Rodriguez-Pose and Tselio [2012] is particularly relevant because it includes regional physical capital, which is not included in the other studies. They examined the effect of increased regional schooling and infrastructure on workers' salaries in 96 regions in 14 countries in the European Union during 1994-2001. A partial summary of their results is shown in Table 1. The effect denominated "regional schooling" in the table is the total external effect on a worker's salary, including the effects of the level of education in the household, the region, and the neighboring regions. The coefficients on individual and regional schooling are comparable, but the coefficients on schooling and regional infrastructure are not comparable.

\section{Table 1}

Effect of Schooling and Physical Capital on Worker Salaries in the European Union [Dependent variable is $\log$ (wages)]

\begin{tabular}{|l|c|c|c|}
\hline & 1 & 2 & 3 \\
\hline Individual's schooling & .121 & .121 & .121 \\
\hline Regional schooling & & .099 & .076 \\
\hline Regional Infrastructure & & & .210 \\
\hline
\end{tabular}


Since the estimated effect of regional schooling declines when regional infrastructure is included (column 3), the estimated coefficient on regional schooling in column 2 implicitly measures the combined external effects of regional human capital and regional physical capital. So the implications of the results in column 3 are that the external effect of increased schooling on personal income is $63 \%$ of its direct effect and that the regional level of physical capital has an additional external effect on this income. In terms of the components of the marginal products of the Mankiw, Romer, and Weil aggregate production function, the three effects in column 3 correspond to the $\beta$ share of MPH, the $1-\alpha-\beta$ share of MPH (that accrues to labor L), and the 1- $\alpha-\beta$ share of MPK (that also accrues to labor L).

Researchers have long hypothesized that (physical) capital and skill are complementary, which implies that increases in one type of capital raises the marginal product of the other type. This effect is assumed in the aggregate production function in equation (1), since an increase in human capital raises the marginal product of physical capital (and vice-versa):

7) $\quad \mathrm{MPK}=\partial \mathrm{Y} / \partial \mathrm{K}=\mathrm{A}^{1-\alpha-\beta} \alpha(\mathrm{K} / \mathrm{L})^{\alpha-1}(\mathrm{H} / \mathrm{L})^{\beta}$

In a market economy an increase in the MPK leads to increased investment in physical capital and an increase in the stock of physical capital. Solving (7) for K/L yields:

$$
\mathrm{K} / \mathrm{L}=(\alpha / \mathrm{MPK})^{1 / 1-\alpha}(\mathrm{A})^{(1-\alpha-\beta) /(1-\alpha)}(\mathrm{H} / \mathrm{L})^{\beta / 1-\alpha}
$$

Grier [2002 and 2005] estimates a system of equations including equation (8) and the analogous equation for $\mathrm{H} / \mathrm{L}$ as a function of $\mathrm{K} / \mathrm{L}$ for Latin America and sub-Saharan Africa. She shows that both measures of capital are endogenous, so that they simultaneously determine each other. Since these two equations are both a reduced form of the Mankiw, Romer, and Weil aggregate production function, her results support the validity of this function. 
Lopez-Baso and Moreno [2008] estimate the equation for K/L in equation (8) across regions in Spain during 1980-2000. They find that a one-year increase in average regional schooling raised the regional capital stock by $19 \%$ at the beginning of their period and by $13 \%$ at the end of the period. Becker, Hornung, and Woessmann [2011] examine the effect of more schooling on regional industrialization in Prussia in the $19^{\text {th }}$ century. They find that higher regional basic or middle schooling raised regional factory employment in 1816 and in 1849 .

There are three pertinent implications for development accounting in these empirical results. First, aggregate human capital has large external regional effects on the income accruing to (unschooled) labor income and to physical capital, which means that aggregate human capital is not paid its social marginal product. Second, these findings are consistent with the implicit assumption in the aggregate production function that the aggregate factors have external effects on national income. Third, the assumption in development accounting that aggregate factors of production are paid their social marginal products is rejected.

Even if the private marginal product is less than the social marginal product, as specified in Mankiw, Romer, and Weil's aggregate production function, the quantitative relationship between these two marginal products across economies might not correspond to the model's specification. Breton [2013] evaluates whether the model's prediction of the relationship between the social and private marginal products of human capital is consistent with the actual relationship across 36 countries. He finds that the estimated relationship in 1990 is consistent with the actual relationship in countries at different levels of development. Figure 1 shows the estimates of the private and external marginal products of human capital in that study. The social marginal product is the sum of the private and external marginal products. 
The aggregate production function specifies that the private marginal product of physical capital is the $\alpha$ share of its social marginal product. There do not appear to be any analyses in the empirical literature comparing the magnitude of these two marginal products. Researchers have not been as concerned about whether aggregate physical capital has external effects, and there is no simple way to identify the private marginal product of physical capital.

Figure 1

\section{Direct and External Marginal Products of Human Capital in 1990}

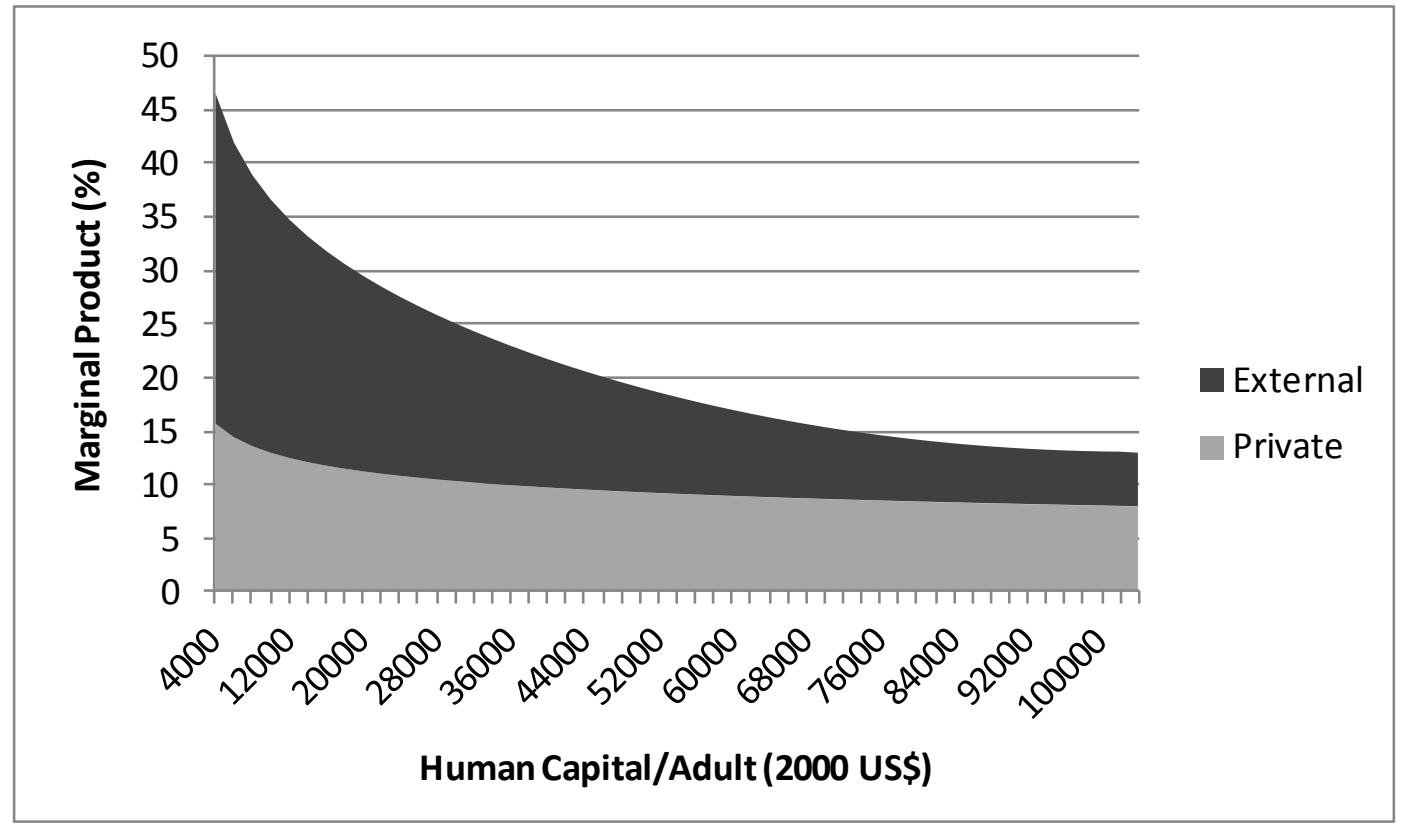

Even without precise estimates of the private MPK, the predicted private MPK is so much smaller than the social marginal product that it should be possible to determine whether this prediction has any validity. The first step in this process is to estimate physical capital's social marginal product. Caselli and Feyrer [2007] argue that estimates of physical capital stocks based on national investment rates in the Penn World Table (PWT) underestimate the actual 
capital stock because estimates of stocks based on these rates do not account for nonreproducible capital (e.g., land and natural resources). They estimate social MPKs for 53 countries using the PWT investment rates with and without the income that accrues to the nonreproducible capital.

In the case of the U.S., Caselli and Feyrer estimate that in 1996 the unadjusted social MPK was about 12 percent real, while the social MPK for reproducible physical capital was about 9 percent real. Using the estimate for reproducible physical capital and an assumed $\alpha=$ 0.35, Mankiw, Romer, and Weil's aggregate production function predicts that the U.S. private MPK for reproducible capital in 1996 was only 3.1 percent.

Private returns on capital exhibit cyclical variation, so the estimated average return on private capital over a period provides a more robust measure than a one-year estimate for 1996. However, private returns on invested capital over a period are not the same as the marginal product of physical capital, which is a return that holds constant the other (micro) factors of production:

9) $\quad$ Private return $=\mathrm{d} \mathrm{Y} / \mathrm{dK}=\partial \mathrm{Y} / \partial \mathrm{K}+(\partial \mathrm{Y} / \partial \mathrm{H} * \partial \mathrm{H} / \partial \mathrm{K})+(\partial \mathrm{Y} / \partial \mathrm{L} * \partial \mathrm{L} / \partial \mathrm{K})$

Since the private return on invested capital measured over time does not hold these other factors constant, the private return is likely to be larger than the private marginal product of physical capital, which is limited to the first of the three terms in equation (9).

One proxy for the private return on capital is the average real cost of financial capital, which in an equilibrium capital market should equal the real marginal product of invested capital. This cost can be approximated by the real weighted average cost of capital (WACC) for private U.S. companies. 
McGrattan and Prescott [2003] estimate that between 1960 and 2002 the real return on equity in the U.S. averaged about 5.0 percent and the real return on corporate debt averaged about 3.8 percent. Assuming a 1.5 debt/equity ratio, this yields an average WACC during this period of 4.3 percent.

Between 1960 and 2002, the rising level of physical capital in the U.S. raised firm income, which is likely to have raised firm investment in human capital. As a consequence, the term $\partial \mathrm{Y} / \partial \mathrm{H}^{*} \partial \mathrm{H} / \partial \mathrm{K}$ is likely to have been positive over this period, so the private MPK is likely to have been less than the 4.3 percent average WACC. While this calculation is very rough, it provides evidence that the relationship between the private and social MPKs in the U.S. in 1996 is consistent with the prediction of Mankiw, Romer, and Weil's aggregate production function. This calculation indicates that the U.S. private MPK was much closer to 3.1 percent than to 9 percent, which is further evidence that aggregate factors of production are not paid their social marginal products.

\section{The Current Methodology in Development Accounting}

Hall and Jones [1999] and Caselli [2004] use the following aggregate production function to determine the relative shares of national income due to differences in capital and in the residual TFP across countries:

10) $\quad \mathrm{Y}=\mathrm{AK}^{\alpha}\left(\mathrm{H}^{\gamma}\right)^{1-\alpha}$

Where $\gamma$ is the observed private effect of human capital on personal income and the 1- $\alpha$ exponent is included to convert the effect of human capital on the workers' share of national income to its effect on national income.

This aggregate production function differs from Mankiw, Romer, and Weil's function in that it attributes the entire worker share of national income (1- $\alpha)$ to the effect of human capital 
instead of the smaller $\beta$ share. Since the cross-country evidence supports Mankiw, Romer, and Weil's function, with a value of $\beta<1-\alpha$ and implicitly a separate variable for (unschooled) labor [Breton, 2011], the function in equation (10) is mis-specified.

The effect of human capital $[\gamma(1-\alpha)]$ in Hall and Jones/Caselli's development accounting estimates is much smaller than in Breton's [2013] estimate of the aggregate production function because 1) the private effect of human capital is only 35 percent (the $\beta$ share) of the macro effect and 2) Hall and Jones/Caselli assume that the private effect of schooling $(\gamma)$ declines as countries become more educated.

Overall Hall and Jones/Caselli's production function attributes an effect of human capital on national income that is less than half of Breton's estimate of this effect in Mankiw, Romer, and Weil's function. Since Hall and Jones/Caselli underestimate the effect of human capital on national income, they overestimate the residual effect due to differences in national TFP.

The whole point of development accounting was to use the observed private marginal product of schooling to estimate the social marginal product and thereby calculate the residual TFP not explained by either physical capital or human capital. But since the private marginal product cannot be used to represent the social marginal product, development accounting cannot be carried out without an estimate of the relationship between the private marginal product and the social marginal product. Since this relationship can only be estimated using econometrics, the desirable feature of development accounting, that it could estimate the differences in national TFP from available economic data, turns out to have been based on a mistaken assumption.

\section{Conclusions}

Development accounting is currently carried out with an aggregate production function that includes human capital. This methodology estimates the differences in national TFP across 
countries as a residual after accounting for the effect of physical capital and human capital on national output. This calculation requires estimates of the shares of national income that accrue to physical capital and human capital. Since the share accruing to human capital cannot be observed in the national accounts data, practioners of development accounting estimate this share from the private marginal product of schooling, which is assumed to equal the social marginal product.

This approach is inconsistent with the theoretical relationship between the private marginal product and the social marginal product in the Cobb-Douglas aggregate production function, which specifies that the private share is only a fraction of the social marginal product. The recent empirical literature provides considerable evidence that aggregate capital factors have large external effects, which is consistent with the assumption in the aggregate production function that the private marginal products of human capital and physical capital are much smaller than their social marginal products. As a consequence, the consensus finding in the development accounting literature that differences in capital/worker explain only half of the cross-country differences in national income/worker substantially underestimates the effect of differences in capital/worker and overestimates the effect of differences in national productivity.

If the social marginal product of human capital is not equal to the private marginal product, then development accounting cannot correctly calculate human capital's contribution to national income. Since there is no way to modify its methodology so that it can provide valid results, the practice of development accounting should be abandoned. 


\section{References}

Becker, Sascha O., Hornung, Erik, and Woessmann, Ludger, 2011, "Education and Catch-up in the Industrial Revolution,” American Economic Journal: Macroeconomics, 3, 92-126

Bernanke, Ben S. and Refet S. Gurkaynak, 2001, "Taking Mankiw, Romer, and Weil Seriously," NBER Macroeconomics Annual, v16, 11-57.

Breton, Theodore R., 2004, “Can Institutions or Education Explain World Poverty? An Augmented Solow Model Provides Some Insights,” Journal of Socio-Economics, v33, 45-69 Breton, Theodore R., 2011, “Does Investment in Schooling Raise National Income? Evidence from Cross-Country Studies," Ecos de Economía," v32, 99-120

Breton, Theodore R., 2013, "Were Mankiw, Romer, and Weil Right? A Reconcilation of the Micro and Macro Effects of Schooling on Income" Macroeconomic Dynamics, v17, n5, 10231054

Caselli, Francesco, 2004, “Accounting for Cross-Country Income Differences," NBER working paper 10828, 1-69. Later published in Handbook of Economic Growth, 2005, ed. by P. Aghion, and S. N. Durlauf, volume 1A, chapter 9, pp. 679-741, Elsevier

Caselli, Francesco, and Feyrer, James, 2007, “The Marginal Product of Capital,” Quarterly Journal of Economics, v122, n2, 535-568

Cohen, Daniel, and Soto, Marcelo, 2007, “Growth and Human Capital: Good Data, Good Results," Journal of Economic Growth, v12, n1, 51-76

Dinopoulos, E., and Thompson, P., 1999, "Reassessing the empirical validity of the humancapital augmented neoclassical growth model, Journal of Evolutionary Economics, v9, 135-154 Grier, Robin M., 2002, "On the Interaction of Human and Physical Capital in Latin America," Economic Development and Cultural Change, v50, n4, 891-913 
Grier, Robin M., 2005, “The Interaction of Human an Physical Capital Accumulation: Evidence from Sub-Saharan Africa," Kyklos, v58, n2, 195-211

Hall, Robert E., and Jones, Charles I., 1999, Why Do Some Countries Produce So Much More Output Per Worker Than Others?" Quarterly Journal of Economics, v114, n1, 83-116

Heuermann, Daniel, 2011, "Human Capital Externalities in Western Germany," Spatial Economic Analysis, v6, n2, 139-165

Hsieh, Chang-Tai, and Klenow, Peter J., 2010, “Development Accounting,” American Economic Journal: Macroeconomics, v2, n1, 207-223

Liu, Zhiqiang, 2007, "The External Returns to Education: Evidence from Chinese Cities," Journal of Urban Economics, v61, n3, 542-564.

Lopez-Bazo, Enrique and Rosina Moreno, 2008, "Does Human Capital Stimulate Investment in Physical Capital? Evidence from a Cost System Framework," Economic Modelling, v25, 12951305.

Mankiw, N. Gregory, Romer, David, and Weil, David, 1992, “A Contribution to the Empirics of Economic Growth," Quarterly Journal of Economics, v107, Issue 2, 407-437

McGrattan, Ellen, R., and Prescott, Edward C., 2003, “Average Debt and Equity Returns: Puzzling?," Research Department Staff Report 313, Federal Reserve Bank of Minneapolis Moretti, Enrico, 2004, "Estimating the Social Return to Higher Education: Evidence from Longitudinal and Repeated Cross-sectional Data," Journal of Econometrics, 121, 175-212. Rodriguez-Pose, Andres, and Tselios, Vassilis, 2012, "Individual Earnings and Educational Externalities in the European Union," Regional Studies, v46, n1, 39-57

Sand, Benjamin M., 2013, “A Re-examination of the Social Returns to Education: Evidence from U.S. Cities,” Labour Economics, v24, 97-106 
Solow, Robert M., 1957, “Technical Change and the Aggregate Production Function," The Review of Economics and Statistics, v39, n3, 312-320 